\title{
Iron overload diminishes atherosclerosis in apoE-deficient mice
}

\author{
Elizabeth A. Kirk, ${ }^{1}$ Jay W. Heinecke, ${ }^{2}$ and Renée C. LeBoeuf ${ }^{1}$ \\ ${ }^{1}$ Departments of Pathobiology and Nutritional Sciences, University of Washington, Seattle, Washington, USA \\ ${ }^{2}$ Departments of Medicine, and Molecular Biology and Pharmacology, Washington University, St. Louis, Missouri, USA \\ Address correspondence to: Renée C. LeBoeuf, Departments of Pathobiology, and Nutritional Sciences, Box 353410, \\ Room 305 Raitt Hall, University of Washington, Seattle, Washington 98195, USA \\ Phone: (206) 543-5208; Fax: (206) 685-1696. E-mail: leboeuf@u.washington.edu.
}

Received for publication on June 22, 1999, and accepted in revised form May 3, 2001.

It has been proposed that elevated levels of tissue iron increase the risk for atherosclerosis, perhaps by favoring the formation of pro-atherogenic oxidized LDL. Working with apoE-deficient $\left(a p o E^{-/}\right)$mice, which do not require a high-fat diet to develop atherosclerosis, we compared the effects of standard diet $(0.02 \%$ iron) or a $2 \%$ carbonyl iron diet. After 24 weeks, mice fed the $2 \%$ carbonyl iron diet had twice as much iron in their plasma, a ninefold increase in bleomycin-detectable free iron in their plasma, and ten times as much iron in their livers as control mice. Dietary iron overload caused a modest $(30 \%)$ rise in plasma triglyceride and cholesterol. Nevertheless, this regimen did not exacerbate, but rather reduced the severity of atherosclerosis by $50 \%$, and it failed to elevate hepatic levels of heme oxygenase mRNA, which is induced by many different oxidative insults in vitro. Moreover, hepatic levels of protein-bound dityrosine and ortho-tyrosine, two markers of metal-catalyzed oxidative damage in vitro, failed to rise in iron-overloaded animals. Our observations suggest that elevated serum and tissue levels of iron are not atherogenic in $a p o E^{-/-}$mice. Moreover, they call into question the hypothesis that elevated levels of tissue iron promote LDL oxidation and oxidative stress in vivo.

J. Clin. Invest. 107:1545-1553 (2001).

\section{Introduction}

Iron is one of the most abundant minerals on the planet and is required for life. Yet, it is known to be highly toxic to biological molecules because of its high activity as an oxidizing agent. The severe consequences of aberrant iron metabolism are demonstrated by human genetic diseases including hemochromatosis and Friedrich's ataxia $(1,2)$. A continuing question concerns the role of iron in atherosclerotic vascular disease. Epidemiological and clinical studies have shown that premenopausal women are at lower risk for atherosclerotic vascular disease than men. In 1981, Sullivan (3) proposed that this protective effect might result from lower body stores of iron due to menstruation. However, associations between indicators of body iron stores and heart disease are inconsistent (4, $5)$. In addition, studies performed in hypercholesterolemic animals offer conflicting conclusions (6-8). One found that iron overload increased the rate of atherogenesis (8), one found that iron deficiency was protective (9), and others suggested that iron might not be deleterious $(6,7)$. It is therefore unclear whether iron promotes atherosclerosis.

A potential mechanism for artery wall damage by iron involves modifications of LDL, the major carrier of blood cholesterol in humans (10). Such modifications may be atherogenic because many lines of evidence suggest that LDL, an important risk factor for atherosclerosis, must be oxidatively modified to trigger disease $(11,12)$, and metal-dependent oxidation reac- tions have been shown to occur in vitro (13-15). For example, cultured smooth muscle cells use extracellular iron to modify LDL (13), and metal chelators inhibit LDL oxidation by many types of cells $(13,16,17)$. Moreover, high concentrations of iron (13) and copper $(13,17)$ oxidize LDL in the absence of cells, as does protein-bound iron in hemin (18). Thus, the combination of hyperlipidemia and iron overload may, in particular, promote cardiovascular disease.

Iron has been detected in human atherosclerotic lesions, a microenvironment thought to promote free iron release $(19,20)$. Moreover, redox-active metal ions have been found in tissue homogenates prepared from atherosclerotic lesions $(21,22)$. However, these studies did not report the levels of metal ions in normal aortic tissue subjected to the same analytical procedure.

In the current studies, we tested the hypothesis that iron overload increases the development of atherosclerosis in apoE-deficient $\left(\mathrm{apoE}^{-/-}\right)$mice. We used dietary carbonyl iron to induce iron overload because it rapidly delivers iron to parenchymal cells of target organs (23-25). We chose the hyperlipidemic apoE ${ }^{-/-}$mouse because it develops atherosclerosis spontaneously when fed rodent chow $(26,27)$. Therefore, dietary iron could be administered in the absence of dietary fat and cholesterol, reducing the potential of dietary lipid oxidation which may have confounded our results. We show that high-iron diets markedly reduced the extent of atherosclerosis in apoE $/-$ mice. Hepatic levels of ortho-tyrosine and dityrosine, products of protein oxi- 
dation, were not different for mice fed the low- and high-iron diets. Overall, our data do not support the concept that iron overload promotes atherosclerosis.

\section{Methods}

Animals. Female apoE ${ }^{-/-}$mice, aged 6-8 weeks (The Jackson Laboratories, Bar Harbor, Maine, USA) were maintained in a temperature-controlled room $\left(22^{\circ} \mathrm{C}\right)$ with a 12-hour light/dark cycle and given free access to food and water. Food was removed from the mice 4 hours before the collection of blood from the retroorbital plexus. Serum was stored at $-70^{\circ} \mathrm{C}$ until analysis. Mice were killed by cervical dislocation, and whole animals were perfused with $10 \mathrm{ml}$ of antioxidant buffer (100 $\mu \mathrm{M}$ diethylenetriamine pentaacetic acid [DTPA], $100 \mu \mathrm{M}$ butylated hydroxytoluene [BHT], $0.1 \%$ ethanol, in PBS, pH 7.4) via the left ventricle. Tissues were snapfrozen in liquid nitrogen and stored at $-70^{\circ} \mathrm{C}$. Tissues used for determination of ortho-tyrosine and dityrosine levels were snap-frozen in antioxidant buffer. The Animal Care and Use Committee of the University of Washington approved this study.

Diets. Mice were fed a pelleted rodent chow (Wayne Rodent BLOX 8604; Harlan Teklad Laboratory, Madison, Wisconsin, USA) for 2 weeks before initiation of feeding with low- and high-iron diets. The low-iron diet contained, by weight, approximately $0.001 \%$ BHT, $24 \%$ protein, $4.5 \%$ crude fiber, and $0.02 \%$ iron (manufacturer's estimate). Wayne Rodent BLOX 8604 in nonpelleted form was mixed (wt/wt) with carbonyl iron (gradeS-3700; ISP Technologies Inc., Wayne, New Jersey, USA) to yield the high-iron diet ( $2 \%$ iron by weight, Teklad Test Diet no. 91091), also containing 0.001\% BHT (25). Diets were stored at $4{ }^{\circ} \mathrm{C}$. Equal numbers of mice were fed the low- and high-iron diets for $6(n=10$ each diet), $12(n=10)$, and 24 weeks $(n=20)$.

FPLC. Serum lipoproteins were separated by FPLC size-exclusion chromatography using a Superose 6 column (Amersham Pharmacia Biotech AB, Uppsala, Sweden). Serum $(100 \mu \mathrm{l})$ was loaded onto the column and eluted with PBS at a flow rate of $0.2 \mathrm{ml} / \mathrm{min}$ at $4^{\circ} \mathrm{C}$. Sixty fractions, $500 \mu \mathrm{l}$ each, were collected using a Frac 100 fraction collector (Pharmacia LKB Biotechnology). A $100-\mu l$ aliquot from each fraction was used for total cholesterol determination.

Western blot analysis. Ferritin protein was quantified using immunoblotting. Liver and aortic tissues were homogenized directly into Tripure Isolation Reagent (catalogue no. 1667; Roche Molecular Biochemicals Inc., Indianapolis, Indiana, USA). Aliquots of $50 \mu \mathrm{g}$ protein from liver, $5 \mu \mathrm{g}$ protein from aortic tissue, or $10 \mu \mathrm{l}$ of serum were prepared from mice fed low- or high-iron diets for 24 weeks. Samples were subjected to SDSPAGE and blotted onto nitrocellulose membranes (Schleicher \& Schuell Inc., Keene, New Hampshire, USA). Membranes were incubated with polyclonal Ab prepared in rabbit anti-human ferritin heavy chain (1:5000 dilution; Roche Molecular Biochemicals Inc.), followed by incubation with iodinated protein A (cata- logue no. NE146L; NEN Life Science Products Inc., Boston, Massachusetts, USA). Standard curves were prepared using type 1 horse spleen ferritin (Sigma Chemical Co., St. Louis, Missouri, USA). Quantification of band intensities were determined using the Cyclone Phosphorimaging analysis system (Packard Instrument Co., Meriden, Connecticut, USA).

Serum lipids. Serum cholesterol levels were determined using a colorimetric kit (Diagnostic Chemicals Ltd., Oxford, Connecticut, USA) with cholesterol standards (Preciset no. 12552; Roche Molecular Biochemicals Inc.). Plasma triglyceride levels were determined colorimetrically after removal of free glycerol (diagnostic kit no. 450032; Roche Molecular Biochemicals Inc.).

Iron status. Serum nonheme iron levels and total ironbinding capacity (TIBC) were determined either electrochemically as described (25) by using the Ferrochem II Serum Iron/TIBC analyzer (Environmental Sciences Associates, Bedford, Massachusetts, USA) or colorimetrically (Wako Fe B and UIBC kits; Wako Pure Chemical Industries Ltd., Osaka, Japan). Tissue iron concentrations were determined as described (25).

Mass spectrometric analysis. Hepatic tissue was dialyzed, delipidated, and acid hydrolyzed as described previously (28). Amino acids were isolated by solidphase extraction on a C18 column, converted to their $n$-propyl heptafluorobutyryl acid derivatives, and then quantified using isotope dilution negative-ion electron capture gas chromatography/mass spectrometry (GC/MS) with a Hewlett Packard 5890 gas chromatograph interfaced with a Hewlett Packard 5988A mass spectrometer with extended mass range (J\&W Scientific Folsom, Connecticut) (28). Under these chromatography conditions, authentic compounds and isotopically labeled standards were base line separated and exhibited retention times identical to those of analytes derived from tissue samples. The limit of detection (signal/noise >10) was less than 1 pmol for all of the amino acids. The ions used for detecting analyte and internal standard were: phenylalanine, $\mathrm{m} / \mathrm{z} 383$ and 389 ions; tyrosine, $\mathrm{m} / \mathrm{z} 417$ and 423 ions; orthotyrosine, $\mathrm{m} / \mathrm{z} 595$ and 601 ions; $o, o^{\prime}$-dityrosine $\mathrm{m} / \mathrm{z}$ 1208 and 1220 ions.

Bleomycin-chelatable iron. Concentrations of bleomycin-chelatable iron were measured by the Sohalmodified method of Gutteridge et al. $(29,30)$. Solutions were passed over a Chelex (Bio-Rad Life Science Research Group, Hercules, California, USA) column to remove transition metal ions. Liver tissue, collected in buffer lacking DTPA ( $30 \mathrm{mg}$ in $300 \mu \mathrm{l}$ of $150 \mathrm{mM}$ $\mathrm{NaCl}$ ), was homogenized and centrifuged at $10,000 \mathrm{~g}$ for 10 minutes at $4^{\circ} \mathrm{C}$. The supernatant was removed, centrifuged again, and an aliquot of the supernatant was diluted 1:50 with water. The protein content of the supernatant was determined using the Lowry method. Mouse serum was centrifuged at $10,000 \mathrm{~g}$ for $10 \mathrm{~min}-$ utes. An aliquot of the tissue or serum supernatant (5 $\mu \mathrm{l}$; diluted 1:1 [vol/vol] with water) was added to $200 \mu \mathrm{l}$ of calf thymus DNA $(1 \mathrm{mg} / \mathrm{ml}), 10 \mu \mathrm{l}$ of bleomycin $(1.5$ 
$\mathrm{U} / \mathrm{ml}), 50 \mu \mathrm{l}$ of $\mathrm{MgCl}(50 \mathrm{mM})$, and $50 \mu \mathrm{l}$ of Tris $(1 \mathrm{M}$, $\mathrm{pH} 7.4)$ in a $1.5-\mathrm{ml}$ microcentrifuge tube. Freshly prepared ascorbate $(25 \mu \mathrm{l}$ of a $7.5-\mathrm{mM}$ solution) was added, and the mixture was incubated at $37^{\circ} \mathrm{C}$ for 1 hour. After the addition of $50 \mu \mathrm{l}$ of EDTA $(100 \mathrm{mM})$, $250 \mu \mathrm{l}$ of thiobarbituric acid (1\% [wt/vol] in $50 \mathrm{mM}$ $\mathrm{NaOH})$, and $250 \mu \mathrm{l}$ of $\mathrm{HCl}(3 \mathrm{~N})$, the sample was heated at $85^{\circ} \mathrm{C}$ for 20 minutes. Samples were vortexed, centrifuged at $10,000 \mathrm{~g}$ for 10 minutes, and the supernatants were analyzed with a Beckman DU7 Spectrophotometer (Beckman Instruments Inc. Fullerton, California, USA). A standard curve prepared with solutions of ferrous iron sulfate was used to calculate concentrations of free iron. To correct for nonspecific absorbance, we subtracted $\mathrm{A}_{512}$ from $\mathrm{A}_{532}$.

Quantification of $m R N A$. Hepatic total RNA was isolated with Tripure Isolation Reagent (Roche Molecular Biochemicals Inc.). The mRNA was then isolated using the Polytract mRNA Isolation System IV (catalogue no. Z5310, Promega Corp., Madison, Wisconsin, USA) and separated on $1.2 \%$ agarose denaturing gels before transfer to nylon membranes (Nytran Plus; Schleicher \& Schuell Inc.). The cDNA probes for hybridization to specific mRNAs were generated in a two-step process using PCR. First, RT-PCR was performed using mRNA isolated from $\mathrm{C} 57 \mathrm{BL} / 6$ mice fed rodent chow as a template to generate small amounts of DNA. Second, this DNA was used as a template to generate probes for Northern blot analyses. Primers were designed using Primer 3 Output (31) based on sequence information in GenBank (32). Primer sequences used were: L-gulono- $\gamma$ lactone oxidase, $5^{\prime}$-TGCCACAGTTCCACCTTCT and $3^{\prime}$ GGTTGCTGCTCTCCTTCTTG; catalase, 5'-CCTCGTTCAGGATGTGGTTT and ${ }^{\prime}$-CTGGTCGGTCTTGTAATGGA; serum amyloid A (SAA), 5'-TGACAGCCAAAGATGGGTC and $3^{\prime}$-TGGGAACAACAGGAAGAGAAA; heme oxygenase, 5'-ACTGGTGATGGCTTCCTTGT and 3'-TGAGGGACTCTGGTCTTTGTG; manganese superoxide dismutase (MnSOD), 5'-GAGAGCAGCGGTCGTGTAA and 3'-CCTTATTGAAGCCAAGCCAG; CuZn superoxide dismutase (CuZnSOD), 5'-CTTCTCGTCTTGCTCTCTCT and $3^{\prime}$ CTTCATTTCCACCTTTGCCC; extracellular eCuZnSOD, 5'-TGGTTGAGAAGATAGGCGACA and 3'-CCCAAGATGGAGTGCGGT; glutathione peroxidase, 5 '-GGACTACACCGAGATGAACGA and $3^{\prime}$-GGGACAGCA-GGGTTTCTATG; glutathione reductase, $5^{\prime}$-GTAGGAAGCCCACCACAACT and $3^{\prime}$-ATCTCATCACAGCCAATCCC; and ferritin heavy chain, 5'-TGAAGCCTTAGGGCAGTACGACT and $3^{\prime}$ TTATGGCTCGCATCTTGTGAACT.

RT-PCR conditions were identical for all primer sets: initial temperature of $50^{\circ} \mathrm{C}$ for 30 minutes followed by 35 cycles of 1 minute at $95^{\circ} \mathrm{C}, 1$ minute at $50^{\circ} \mathrm{C}$, and 1 minute at $68^{\circ} \mathrm{C}$. Bands were isolated from 1.2\% agarose gels (Geneclean Kit; Bio 101 Inc., La Jolla, California, USA). PCR conditions were identical for all sets of primers: 10 minutes at $95^{\circ} \mathrm{C}$, followed by 35 cycles of 1 minute at $95^{\circ} \mathrm{C}, 1$ minute at $50^{\circ} \mathrm{C}$, and 1 minute at $68^{\circ} \mathrm{C}$. Probes were labeled by random hexamer labeling, and quantification of spe- cific bands was performed by densitometry (65-700 Imaging Densitometer; Bio-Rad Life Science Research Group) using Molecular Analyst 1.3 software (BioRad Life Science Research Group). The mRNA levels were normalized to GAPDH.

Atherosclerosis lesion analyses. Lesion sizes were quantified in the aortic sinus as described (33). Briefly, the upper sections of the hearts were incubated overnight in methyl Carnoy's fixative and paraffin embedded the following day. Every-other section (10 $\mu \mathrm{m}$ thick) throughout the aortic sinus $(400 \mu \mathrm{m})$ was taken for analysis. Sections were evaluated for lesions after hematoxylin and eosin staining using computer-assisted imaging and the Optimas Image Analysis software package (Bioscan Inc., Edmonds, Washington, USA) (33).

Immunocytochemical staining of aortic sinus sections was done as described previously (33) with some modifications. Paraffin sections were deparaffinized, rinsed in PBS, incubated for 10 minutes in PeroxoBlock (Zymed Laboratories Inc., San Francisco, California, USA), and boiled in $0.01 \mathrm{M}$ citrate buffer, $\mathrm{pH} 6.0$ for 10 minutes. Sections were incubated with rabbit anti-human ferritin (dilution of 1:100) (catalogue no. 605 022; Roche Molecular Biochemicals Inc.) or horseradish peroxidase-labeled rabbit anti-human smooth muscle actin (diluted 1:5) (DAKO Corp., Carpinteria, California, USA) for 2 hours at room temperature. Sections were developed using the Histomouse SP Kit (Zymed Laboratories Inc.) according to the manufacturer's instructions. Slides were counterstained with hematoxylin. Control sections were treated without primary $\mathrm{Ab}$ and all control sections remained free of immunostain products.

Statistics. Values are reported as mean plus or minus SEM. Statistical differences were determined using SYSTAT for the Macintosh (SYSTAT Inc., Evanston, Illinois, USA). Statistical differences were determined

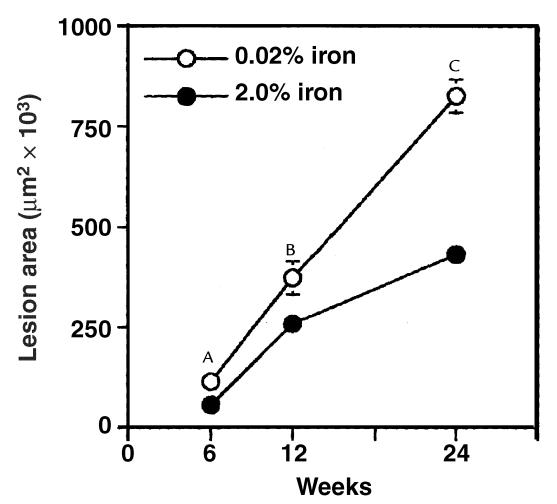

\section{Figure 1}

Aortic sinus lesion area for apoE $\mathrm{E}^{-/-}$mice fed low-iron $(0.02 \%)$ and high-iron (2\%) diets for 6,12 , and 24 weeks. Values are the mean plus or minus SEM for $n=10$ mice at each time point. Lesion areas were determined using computer-assisted morphometric analysis. Standard error bars fall within the symbols in some cases. ${ }^{A} P=0.027 ;{ }^{B} P=0.016 ;{ }^{C} P=0.0001$. 


\section{Figure 2}

Quantification of ferritin protein. Liver, serum, and aortic samples were taken from mice fed the $0.02 \%$ and $2 \%$ iron diets for 24 weeks ( $n=5$ mice per group). Liver and aortic tissues were homogenized directly into Tripure Isolation Reagent, and aliquots of $50 \mu \mathrm{g}$ protein from liver, $5 \mu \mathrm{g}$ protein from aortic tissue, or $10 \mu \mathrm{l}$ serum were subjected to SDS-PAGE and blotted onto nitrocellulose membranes. Membranes were incubated with polyclonal $\mathrm{Ab}$ prepared in rabbit anti-human ferritin heavy chain (1:5000 dilution), followed by incubation with iodinated protein A. A standard curve was prepared with samples of type 1 horse spleen ferritin, and band intensities were determined using phosphorimaging. Units for the $y$ axis are micrograms of ferritin per milligram of protein for liver and serum samples and nanograms of ferritin per milligram of protein for aortic tissue. Standard error bars fall within the symbols in some cases. ${ }^{A} P<0.001$.

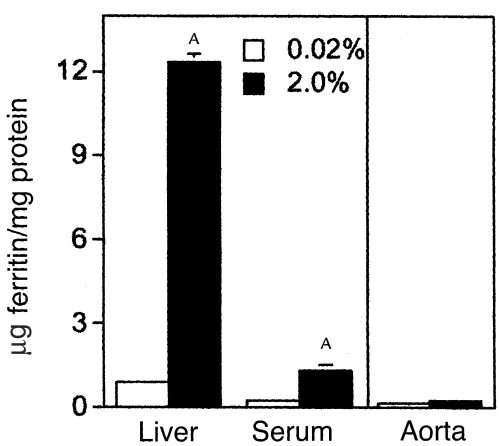

using two-way ANOVA (diet $\times$ time). Post hoc analyses of multiple comparisons were made using Tukey's test for additivity. Pearson's correlation coefficients were used to assess correlations. Some differences were determined using Student's $t$ test. $P$ values less than 0.05 were accepted as statistically significant.

\section{Results}

Atherosclerotic lesions are reduced in high iron-fed mice. Aortic sinus lesion sizes were significantly smaller for mice fed high-iron diet as compared with mice fed the low-iron diet at all time points (Figure 1). Twofold reductions in the mean values were seen at 6 and 24 weeks, and a 30\% decrease was seen at 12 weeks. The rate of lesion formation in the iron-fed mice occurred at a decreased rate between 12 and 24 weeks compared with 6 and 12 weeks, suggesting that the rate of lesion progression decreased as iron levels increased. Overall lesion architecture for mice from both diet groups was similar and showed core areas consisting of macrophages and necrotic tissue with fibrous caps of smooth muscle cells (data not shown). This composition is typical for apoE $\mathrm{E}^{-/-}$mice $(26,27)$. Thus, high-iron diet feeding induced an early reduction in lesion area that was maintained for 24 weeks.

Massive iron overload occurs in mice fed $2 \%$ carbonyl iron. Evidence for increased body iron stores was seen as

\section{Figure 3}

Immunostaining for ferritin and $\alpha$-actin at the artery wall. ApoE ${ }^{-/-}$mice were fed the high-iron $(2.0 \%)$ diet for 24 weeks, and $10-\mu \mathrm{m}$ thick cryostat sections were taken at the aortic sinus. Serial sections for mice fed the low-iron diet ( $\mathbf{a}$ and $\mathbf{b}$ ) and high-iron diet ( $\mathbf{c}$ and $\mathbf{d}$ ) are shown and stained for ferritin ( $\mathbf{a}$ and $\mathbf{c}$ ) and $\alpha$-actin ( $\mathbf{b}$ and $\mathbf{d}$ ). The $\alpha$-actin epitopes were used to delineate the presence and location of smooth muscle cells. Macrophage foam cells can be seen for high iron-fed mice as a bulbous cap on the right portion of each section. For low iron-fed mice, macrophage foam cells are seen below the endothelium and interspersed within the lesion. $\times 400$. early as 6 weeks for $2 \%$ carbonyl iron-fed mice (Table 1 ). The iron content for liver and spleen were 13-fold and threefold higher, respectively, for high iron as compared with low iron-fed mice $(P<0.0001)$, and this difference was maintained at 12 (liver, spleen; $P<0.001$ ) and 24 weeks (liver; $P<0.001$ ). Serum iron levels at 12 weeks and 24 weeks were twofold higher for high iron-fed as compared with low iron-fed mice $(P<0.0004)$. Transferrin was completely saturated with iron at 12 and 24 weeks $(97 \%$ and $94 \%$ saturated, respectively). Heart iron content was significantly greater for high-iron than low iron-fed mice at 12 weeks. Body weights for mice fed low and high iron diets for 24 weeks were not significantly different.

Elevations in tissue iron stores is normally accompanied by increases in the primary iron storage protein, ferritin. Levels of ferritin protein as quantified by immunoblotting (Figure 2) were significantly higher in liver and serum from mice fed the $2 \%$ iron diet than from controls, consistent with tissue-iron enrichment. Ferritin protein in aortic tissue was comparable between diet groups. However, it was difficult to assess aortic ferritin because of the small amount of tissue. 
Table 1

Tissue and serum iron parameters for apoE $\mathrm{E}^{-/-}$mice fed $0.02 \%$ and

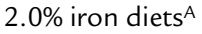

\begin{tabular}{|c|c|c|c|c|}
\hline Tissue & Diet & 6 weeks & 12 weeks & 24 weeks \\
\hline Serum & $0.02 \%$ & ND & $284 \pm 22$ & $172 \pm 17$ \\
\hline Iron & $2.0 \%$ & ND & $431 \pm 25$ & $473 \pm 41$ \\
\hline$(\mu \mathrm{g} / \mathrm{dl})$ & $P$ & & $<0.0004$ & $<0.0006$ \\
\hline \multirow[t]{2}{*}{ TIBC } & $0.02 \%$ & ND & $548 \pm 20$ & $524 \pm 27$ \\
\hline & $2.0 \%$ & ND & $442 \pm 23$ & $488 \pm 63$ \\
\hline$(\mu \mathrm{g} / \mathrm{dl})$ & $P$ & & $<0.003$ & 0.665 \\
\hline TfSat & $0.02 \%$ & ND & $51 \pm 2$ & $33 \pm 5$ \\
\hline \multirow{2}{*}{ (\%) } & $2.0 \%$ & ND & $97 \pm 2$ & $94 \pm 1$ \\
\hline & $P$ & & $<0.0001$ & $<0.0001$ \\
\hline Liver & $0.02 \%$ & $243 \pm 19$ & $320 \pm 26$ & $406 \pm 33$ \\
\hline Iron & $2.0 \%$ & $3227 \pm 203$ & $3475 \pm 201$ & $5593 \pm 325$ \\
\hline$(\mu \mathrm{g} / \mathrm{g})$ & $P$ & $<0.0001$ & $<0.0001$ & $<0.0001$ \\
\hline Spleen & $0.02 \%$ & $1387 \pm 64$ & $2196 \pm 180$ & ND \\
\hline Iron & $2.0 \%$ & $3660 \pm 238$ & $6469 \pm 470$ & ND \\
\hline$(\mu \mathrm{g} / \mathrm{g})$ & $P$ & $<0.0001$ & $<0.0001$ & \\
\hline Heart & $0.02 \%$ & $259 \pm 16$ & $281 \pm 8$ & ND \\
\hline Iron & $2.0 \%$ & $287 \pm 11$ & $366 \pm 15$ & ND \\
\hline$(\mu \mathrm{g} / \mathrm{g})$ & $P$ & 0.156 & $<0.0001$ & \\
\hline
\end{tabular}

A Data presented as mean plus or minus SEM for $n=4-10$ mice. ND, not determined; Tf Sat, transferrin saturation.

To further study ferritin expression at the artery wall, immunocytochemistry was used. Strong Ab staining for ferritin was seen in aortic lesion sections prepared from high iron-fed (Figure 3c) but not low iron-fed mice (Figure 3a). Ferritin epitopes seen in high iron-fed mice colocalized primarily with endothelial cells and macrophages, as evidenced by the lack of colocalization with epitopes for smooth muscle cells (Figure $3 \mathrm{~d}$ ). The appearance of ferritin protein in lesions was not accompanied by a severe accumulation of iron, as monitored by Perl's Prussian blue staining, though a few cells were reactive. In contrast, Prussian blue staining material was detected widely in aortic adventitia, myocardium, and pericardium in the highiron mice, and lesion staining involved only a few cells (data not shown). Overall, the $2 \%$ iron diet completely saturated transferrin with iron, dramatically increased serum and tissue iron levels, and elevated lesion ferritin protein, as compared with low iron-fed mice.

\section{Figure 4}

Lipoprotein profiles for apoE-/- mice fed low-iron (0.02\%) and high-iron (2\%) diets for 6 weeks. Lipoproteins were separated by FPLC using a Superose 6 column as described in Methods. Cholesterol (a) and triglyceride (b) concentrations were determined colorimetrically and are normalized to total plasma levels. Values are shown for low iron-fed (open symbols) and high iron-fed (filled symbols) mice. Fractions $10-20$ contain VLDL, fractions $21-27$ contain LDL, and fractions 28-35 contain HDL.
Serum and tissue lipids do not contribute to lesion formation. The reduction in atherosclerotic lesion sizes could result from a reduction in the concentration of circulating lipids due to feeding the high-iron diet. To test this possibility, serum total cholesterol and triglyceride, as well as hepatic lipid levels, were quantified. Importantly, serum lipids were either not significantly different or were highest for the $2 \%$ iron-fed group. Serum total cholesterol levels were similar between diet groups at 6 weeks ( $313 \pm 13$ and $271 \pm 18 \mathrm{mg} / \mathrm{dl}$ for $0.02 \%$ and $2 \%$ iron fed, respectively) and 12 weeks (363 \pm 18 and $390 \pm 18 \mathrm{mg} / \mathrm{dl}$ for $0.02 \%$ and $2 \%$ iron fed, respectively), and increased significantly for high iron-fed mice (431 $\pm 10 \mathrm{mg} / \mathrm{dl}$ ) as compared with low iron-fed mice (322 $\pm 11 \mathrm{mg} / \mathrm{dl} ; P<0.0001)$ at 24 weeks. Serum triglyceride levels were consistently higher for $2 \%$ carbonyl iron-fed mice $(61 \pm 6 \mathrm{mg} / \mathrm{dl})$ as compared with control mice (43 $\pm 3 \mathrm{mg} / \mathrm{dl} ; P<0.0001-0.004$ at 12 and 24 weeks) at each time point. No differences were seen between diet groups with respect to hepatic cholesterol and triglyceride levels (data not shown).

Altered distribution of serum lipids among lipoproteins also did not account for changes in aortic sinus lesion sizes between diet groups. Examination of the lipoprotein profile after FPLC showed nearly identical patterns for the high iron- and low iron-fed mice at 6 weeks (Figure 4). Collectively, these observations indicate that alterations in serum lipoproteins did not contribute to the reduction in aortic sinus lesion sizes seen for the high iron-fed mice.

Dietary iron overload does not induce hepatic protein oxidation. Aromatic amino acids are important targets for metal ion-catalyzed damage (12). To test whether iron overload could mediate protein oxidation, ortho-tyrosine and dityrosine, characteristic products of protein oxidation $(28,34)$, were measured in liver samples from mice fed high- and low-iron diets. Livers were used because of the quantity of tissue available and the
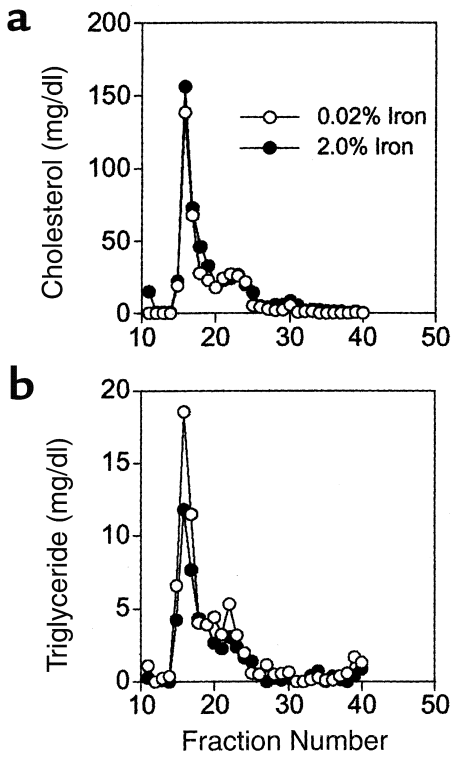

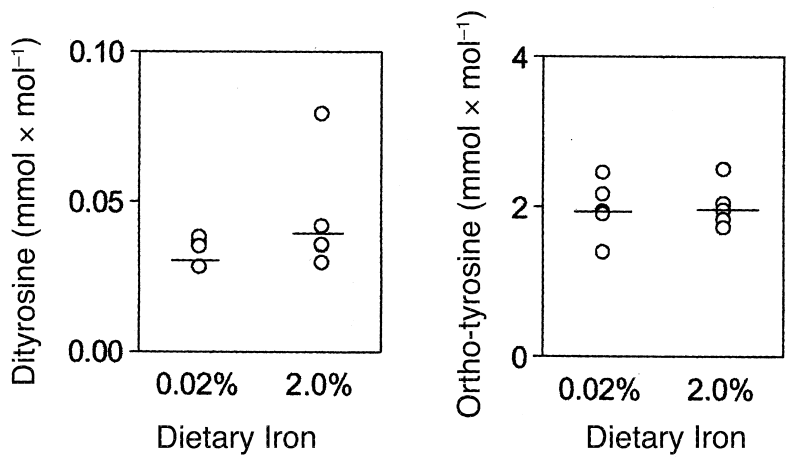

\section{Figure 5}

Hepatic ortho-tyrosine and dityrosine levels for apoE-/- mice fed low-iron $(0.02 \%)$ or high-iron (2.0\%) diets for 24 weeks. Values for individual samples are shown, and the bars are means $(n=5$ mice). Levels were determined using isotope-dilution gas chromatographymass spectrometry. Tyrosine oxidation products were quantified relative to total tyrosine levels. No significant differences were seen between diet groups.

marked elevations in iron content achieved after feeding mice $2 \%$ carbonyl iron. Hepatic levels of ortho-tyrosine and dityrosine did not differ between mice fed the lowand high-iron diets (Figure 5), suggesting that protein oxidation was not provoked by dietary iron overload.

Dietary iron overload fails to induce a general increase in $m R N A$ for antioxidant enzymes. Since it is hypothesized that high iron stores may promote an oxidative environment, we examined the possibility that iron overload might induce the hepatic expression of a panel of enzymes associated with antioxidant defenses (L-gulono$\gamma$-lactone oxidase and heme oxygenase), detoxification of reactive oxygen species (catalase, $\mathrm{MnSOD}, \mathrm{CuZnSOD}$, eCuZnSOD, glutathione peroxidase, and glutathione reductase), and inflammation (serum amyloid $\mathrm{A}$ ). Three enzymes showed altered mRNA levels due to high-iron feeding. The mRNA levels were reduced (L-gulono- $\gamma$-lactone oxidase and catalase) or increased (serum amyloid A) by approximately threefold $(P<0.0001)$ (Figure 6) upon feeding the high-iron diet for 24 weeks. The mRNA levels for the remaining six enzymes did not differ significantly between dietary iron groups. These data suggest that mRNA levels of certain genes are sensitive to tissue iron content, but argue against an overall increase in oxidative stress in the liver.

Levels of catalytically active iron increase in serum and liver of iron-overloaded mice. To determine whether raising levels of protein-bound iron increases levels of catalytically active transition metal ions, serum and liver concentrations of bleomycin-chelatable iron in mice fed the low- or high-iron diet were determined $(29,30)$. This assay relies on the ability of redox-active transition metals to generate malondialdehyde by oxidizing DNA. The malondialdehyde then is reacted with thiobarbituric acid to obtain a pink chromophore with maximum absorbance at $532 \mathrm{~nm}$. All eight serum samples from mice fed the high-iron diet turned pink during this assay, exhibiting an absorbance peak at approxi- mately $532 \mathrm{~nm}$ (Figure 7a). In contrast, none of the ten serum samples from the mice fed low-iron turned pink or developed the 532-nm peak, suggesting that the low level of absorbance we observed was nonspecific or due to light scatter. Low levels of malondialdehyde were also observed in the livers of iron-fed animals. Quantification revealed that the level of free iron in the serum of animals fed the high-iron diet was nine times that in the control-animal samples: $9.0 \pm 1.8 \mu \mathrm{M}$ versus $1.0 \pm 0.8 \mu \mathrm{M}$ (Figure $7 \mathrm{~b}$ ). A twofold increase in free iron levels was observed in livers of the iron-fed mice (3.0 \pm $0.8 \mathrm{nmol} / \mathrm{mg}$ protein versus $6.6 \pm 3.1 \mathrm{nmol} / \mathrm{mg}$ protein; $n=5, P<0.02)$. These observations indicate that the serum and liver from the mice on the high-iron diet contained higher levels of catalytically active metal ions than that from the animals on the control diet.

\section{Discussion}

We hypothesized that diet-induced iron overload would exacerbate the atherosclerotic process and do so by increasing oxidative stress. Surprisingly, we discovered that iron overload reduced the severity of atherosclerosis in apoE-null mice. This was especially remarkable because plasma lipid levels, known to be determinants for atherosclerosis, remained the same or increased modestly during the study. Thus, despite the hyperlipidemia normally exhibited by this strain, iron feeding protected against atherosclerosis.

A key experimental issue is the method of iron delivery because most animal studies have employed parenterally injected iron dextran complexes. This method greatly increases plasma iron levels, but most of the iron is metabolically unavailable $(35,36)$, both because it remains bound to dextran and because iron dextran is scavenged by macrophages. Indeed, iron-deficient anemia can coexist with normal or elevated levels of plasma iron in humans treated with iron dextran (36). When dietary or genetic disorders induce iron overload in humans, the iron-binding capacity of plasma is completely saturated, and most tissue iron is found in

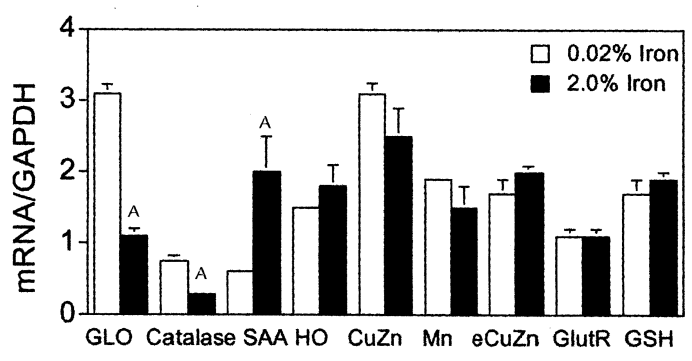

\section{Figure 6}

Quantification of Northern blots of hepatic mRNA. ApoE $\mathrm{E}^{-/-}$mice were fed low-iron (0.02\%) or high-iron (2.\%) diets for 24 weeks ( $n=8$ per diet group). The mRNA levels are normalized to GAPDH levels. The mRNA isolation and Northern blot analyses are described in Methods. ${ }^{A} P<0.001$. GLO, L-gulono-ylactone oxidase; $\mathrm{HO}$, heme oxygenase; GlutR, glutathione reductase; GSH Px, glutathione peroxidase, FerH, Ferritin heavy chain. 
parenchymal cells (37). Our high-iron diet feeding mimicked this latter situation as evidenced by nearly complete saturation of plasma transferrin with iron and hepatocyte loading of iron as assessed chemically and by Perl's Prussian blue staining (data not shown). An important point is that patients with hemochromatosis, a common genetic disease that elevates plasma and tissue iron levels (37), are not at greatly increased risk of atherosclerosis (38). In fact, autopsy studies using quantitative coronary angiography indicate that coronary artery disease is only one third as extensive as in age- and sex-matched subjects (39). Recently, two case-control studies failed to provide evidence in favor of association between mutations in the hemochromatosis gene and atherosclerosis $(40,41)$ or myocardial infarction incidence (42). In contrast to these reports, two recent studies found association between cardiovascular death in postmenopausal women (43) or first acute myocardial infarction (44) and presence of the Cys282Tyr genetic marker for hemochromatosis. However, body iron stores were not evaluated in these subjects. Overall, our results parallel those from studies of patients with clinically diagnosed hemochromatosis. These observations call into question the hypothesis that elevated levels of serum and tissue iron represent an important risk factor for atherosclerosis.

Iron has been detected in human atherosclerotic lesions, and redox-active metal ions have been found in tissue homogenates prepared from atherosclerotic lesions (19-22). We also detected Prussian blue-positive cells in atherosclerotic lesions of the mice fed the highiron diet. However, the majority of iron staining was seen in the adventitial tissue, myocardium, and pericardium, and lesion staining involved only a few cells. Despite the presence of tissue iron in the aortic sinus, these mice exhibited reduced atherosclerosis, suggesting that changes in tissue iron content were not deleterious.

Mice fed the high-iron diet had markedly elevated levels of iron in the liver and blood. However, increased levels of protein-bound iron do not necessarily correlate with catalytically active iron in the artery wall. We were unable to measure the latter directly because only small amounts of atherosclerotic tissue were available. Instead, we quantified levels of redox-active transition metal ions in liver and serum as bleomycin-chelatable iron. This assay measures non-transferrin-bound iron that has the potential of becoming redox active and is believed to reflect levels of catalytically active free iron $(29,30,45)$. Liver from mice fed the $2 \%$ iron diet exhibited a significant twofold increase in bleomycin-chelatable iron compared with control animals. The increase of free iron was even more marked in serum; mice fed the $2 \%$ iron diet had a ninefold higher concentration of bleomycin-chelatable iron than that of control animals. Although the latter appeared to contain a low level of free iron, the affinity constant of transferrin for iron is $10^{34}$ (38), transferrin was only partially saturated with iron in the low iron-fed animals, and this free iron was not associated with the characteristic malondialde- hyde-thiobarbituric acid chromophore detected in the bleomycin assay. In contrast, the chromophore was readily detectable in the serum of the animals fed the high-iron diet. These observations suggest that normal mouse serum contains essentially no free iron. In contrast, the serum of high iron-fed mice clearly contains catalytically active transition metals, presumably iron. Because plasma is likely to be in free equilibrium with the extracellular fluid in the artery wall, detection of free iron in the serum strongly supports the hypothesis that the high-iron diet raises levels of catalytically active transition metal ions in the wall itself without concomitant increases in atherosclerosis.

Previous studies have demonstrated that hydroxyl radical, a reactive intermediate in many metal ion-dependent reactions, elevates levels of oxidized amino acids in LDL and model proteins $(28,34)$. Using a combination of gas chromatography and mass spectrometry, a sensitive and specific analytical method, we demonstrated that overloading mice with iron had no effect on the concentration of either ortho-tyrosine or dityrosine in
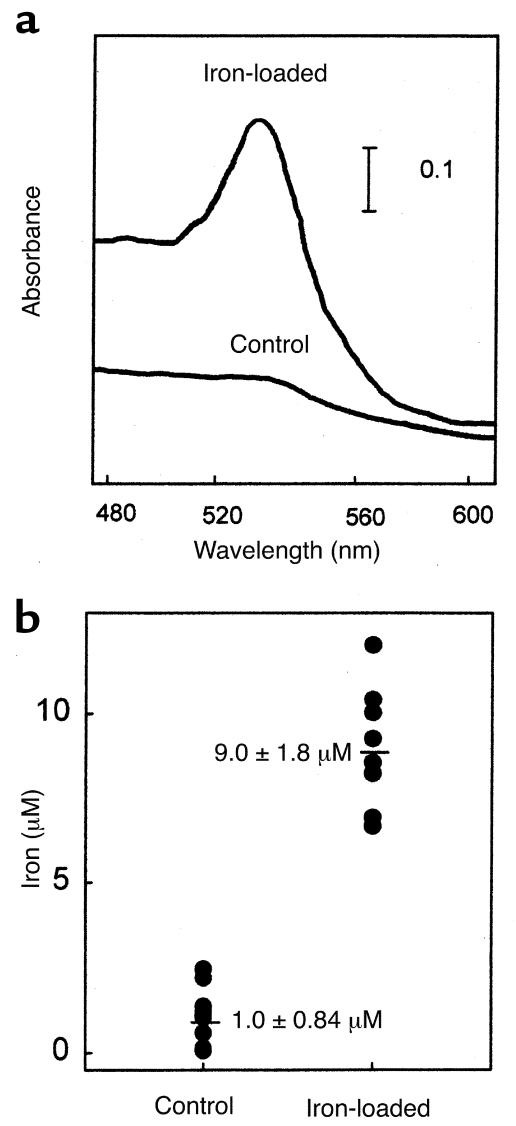

\section{Figure 7}

Bleomycin-chelatable iron in mouse serum. ApoE ${ }^{-/-}$mice were fed lowiron $(0.02 \%)$ or high-iron ( $2 \%$ ) diets for 24 weeks ( $n=8$ per diet group). (a) Visible absorption spectra of the malondialdehyde-thiobarbituric acid chromophore formed using the bleomycin assay and mouse sera. (b) Quantitation of bleomycin-detectable iron in the plasma of mice fed the low-iron and high-iron diet. Mean values (horizontal lines) are significantly different between diet groups at $P<0.005$. 
liver proteins. Treating rabbits with iron also failed to increase peroxidation of plasma lipids as assessed by isotope-dilution mass-spectrometric analysis (6). In fact, the effects of iron status on lipid peroxidation are complex, as both iron deficiency and daily iron feeding promoted lipid peroxidation in rats (46). These observations call into question the hypothesis that iron promotes oxidative damage of proteins and lipids in vivo.

We examined the idea that iron feeding would elevate mRNA levels for a panel of oxidative stress genes in livers of the iron-overloaded mice. The mRNA levels for six of nine enzymes were unchanged due to iron overload. Importantly, we failed to observe an increased level of mRNA for heme oxygenase, an enzyme showing induction of mRNA by a wide variety of oxidative stresses in vitro $(47,48)$. The decrease in L-gulono- $\gamma$-lactone oxidase and catalase mRNA levels seen with high-iron feeding suggests that defense against oxidants and free radicals offered by these systems were not required. Interestingly, marked increases in hepatic levels of serum amyloid A mRNA were associated with increased atherosclerosis in mice with diet-induced hyperlipidemia (49). In contrast, we observed modest increases in serum amyloid A mRNA for mice with reduced atherosclerosis, which suggests that serum amyloid $\mathrm{A}$ is not a consistent marker for extent or risk of atherosclerosis. We are unaware of any previous reports examining serum amyloid A mRNA following iron overload, and further studies are warranted. Overall, the failure of mRNA levels for oxidation-related genes to change further supports the proposal that iron-overloaded tissues were not subjected to excessive oxidative stress.

At every stage of lesion development that we evaluated, the extent of atherosclerosis was less in $\mathrm{apoE}^{-/-}$mice fed the high-iron diet than in the control animals, suggesting that iron overload actually retarded lesion formation. Although the reason for this remains unclear, there are several potential mechanisms. One involves the iron-dependent destruction of bio-active molecules involved in atherogenesis (50), leading to a paradoxical decrease in lesion formation. Another potential mechanism involves regulation of gene expression in the artery wall. It is well known that tissue iron stores directly influence the expression of proteins involved in iron storage and transport (51). We hypothesize that iron regulates the expression of artery wall genes distinct from those directly involved in iron homeostasis. These may include genes for adhesion molecules, scavenger receptors, growth factors, or cytokines. For instance, iron has been shown to regulate transcription of inducible nitric oxide synthase in macrophage cell lines (52). We found significant alterations in the mRNA levels of three genes (L-gulono--lactone oxidase, catalase, and serum amyloid A) heretofore not recognized as responsive to iron in mice fed the high-iron diet. Further studies of such gene regulation are warranted.

Alternatively, a potential protective effect of iron overload involves cellular effects mediated by oxidized LDL. Balla and coworkers showed that endothelial cells exposed to heme become resistant to the toxicity medi- ated by oxidized $\operatorname{LDL}(53,54)$. The proposed mechanism for this effect was increased expression of ferritin, which would then become available to prevent the build up of free iron potentially released after cellular necrosis. However, we failed to detect a marked increase in ferritin levels in the aortic tissue of high iron-fed mice. Moreover, the absolute level of ferritin protein in this tissue was very low compared with liver and serum. It should be noted that we found twofold increase in liver levels of bleomycin-chelatable iron in mice fed the $2 \%$ carbonyl iron diet, which suggests that increases in ferritin were not adequate to prevent a rise in tissue levels of free iron. These observations suggest that an ironinduced increase in the level of ferritin in the aorta is unlikely to account for the decrease in atherosclerosis we observed in iron-fed mice.

In summary, we found that dietary iron overload did not promote atherosclerosis in a $\mathrm{poE}^{-/-}$mice. There were no differences in the levels of protein oxidation markers between diet groups. The mRNA levels of stress-related genes also failed to increase, which suggests that the animals were not under increased oxidative stress due to iron feeding. Our data, taken together with decreased lesion sizes observed in iron overloaded rabbits $(6,7)$, the lack of increased atherosclerosis among individuals with hemochromatosis (7), and the lack of consensus in epidemiological studies $(4,5)$, suggest that elevated iron stores are not an important risk factor for accelerated atherosclerotic vascular disease. Because LDL oxidation plays a critical role in atherogenesis, our results also suggest that iron is not a catalyst for LDL oxidation in the artery wall.

\section{Acknowledgments}

Mass spectrometry experiments were performed at the Washington University School of Medicine Mass Spectrometry Resource. We thank Mark Caldwell for excellent technical assistance and Dianne Mueller for performing the bleomycin-chelatable iron assay. This work was supported by grants from the NIH (DK-02456, HL52848, AG-15013, DK-56341, and RR-00954), the American Heart Association, and the Pharmacia-MonsantoSearle/Washington University Biomedical Program.

1. Himmelmann, A., and Fehr, J. 1999. Cloning of the hereditary hemochromatosis gene: implications for pathogenesis, diagnosis, and screening. J. Lab. Clin. Med. 133:229-236.

2. Delatycki, M.B., et al. 1999. Direct evidence that mitochondrial iron accumulation occurs in Friedreich ataxia. Ann. Neurol. 45:673-675.

3. Sullivan, J.L. 1981. Iron and the sex difference in heart disease risk. Lancet. 1:1293-1294.

4. Meyers, D.G. 1996. The iron hypothesis: does iron cause atherosclerosis? Clin. Cardiol. 19:925-929.

5. Sempos, C.T., Looker, A.C., and Gillum, R.F. 1996. Iron and heart disease: the epidemiologic data. Nutr. Rev. 54:73-84.

6. Dabbagh, A.J., Shwaery, G.T., Keaney, J.F., and Frei, B. 1997. Effect of iron overload and iron deficiency on atherosclerosis in the hypercholesterolemic rabbit. Arterioscler. Thromb. Vasc. Biol. 17:2638-2645.

7. Nadkarni, B.B., and Solomon, R.D. 1966. Effect of iron dextran on atherogenesis in cholesterol and corn oil fed rabbits. Indian J. Med. Res. 54:157-165.

8. Araujo, J.A., et al. 1995. Iron overload augments the development of atherosclerotic lesions in rabbits. Arterioscler. Thromb. Vasc. Biol. 15:1172-1180.

9. Lee, T.-S., Shiao, M.-S., Pan, C.-C., and Chau, L.-Y. 1999. Iron-deficient diet reduces atherosclerotic lesions in apoE-deficient mice. Circulation. 99:1222-1229. 
10. Brown, M.S., and Goldstein, J.L. 1992. Koch's postulates for cholesterol. Cell. 71:187-188

11. Witztum, J.L., and Steinberg, D. 1991. Role of oxidized low density lipoprotein in atherogenesis. J. Clin. Invest. 88:1785-1792.

12. Heinecke, J.W. 1997. Mechanisms of oxidative damage of low density lipoprotein in human atherosclerosis. Curr. Opin. Lipidol. 8:268-274.

13. Heinecke, J.W., Rosen, H., and Chait, A. 1984. Iron and copper promote modification of low density lipoprotein by human arterial smooth muscle cells in culture. J. Clin. Invest. 74:1890-1894.

14. Van Lenten, B.J., et al. 1995. Lipid-induced changes in intracellular iron homeostasis in vitro and in vivo. J. Clin. Invest. 95:2104-2110.

15. Heinecke, J.W., Baker, L., Rosen, H., and Chait, A. 1986. Superoxidemediated modification of low density lipoprotein by arterial smooth muscle cells. J. Clin. Invest. 77:757-761.

16. Morel, D.W., DiCorleto, P.E., and Chisolm, G.M. 1984. Endothelial and smooth muscle cells alter low density lipoprotein in vitro by free radical oxidation. Arteriosclerosis. 4:357-364.

17. Steinbrecher, U.P., Parthasarathy, S., Leake, D.S., Witztum, J.L., and Steinberg, D. 1984. Modification of low density lipoprotein by endothelial cells involves lipid peroxidation and degradation of low density lipoprotein phospholipids. Proc. Natl. Acad. Sci. USA. 81:3883-3887.

18. Balla, G., Jacob, H.S., Eaton, J., Belcher, J., and Vercellotti, G. 1991 Hemin: a possible physiological mediator of low density lipoprotein oxidation and endothelial injury. Arterioscler. Thromb. 11:1700-1711.

19. Schwartz, C.J., Ardlie, N.G., Carter, R.F., and Paterson, J.C. 1967. Gross aortic sudanophilia and hemosiderin deposition. A study on infants, children, and young adults. Arch. Pathol. 83:325-332.

20. Jankus, A., Ardlie, N.G., Edwards, R.G., and Schwartz, C.J. 1967. Marked aortic hemosiderin deposits in a patient with hemochromatosis. Arch. Pathol. 84:418-421.

21. Smith, C., Mitchinson, M.J., Aruoma, O.I., and Halliwell, B. 1992. Stimulation of lipid peroxidation and hydroxyl radical generation by the contents of human atherosclerotic lesions. Biochem. J. 286:901-905.

22. Swain, J., and Gutteridge, J.M. 1995. Prooxidant iron and copper, with ferroxidase and xanthine oxidase activity in human atherosclerotic material. FEBS Lett. 368:513-515.

23. Huebers, H.A., Brittenham, G.M., Csiba, E., and Finch, C.A. 1986. Absorption of carbonyl iron. J. Lab. Clin. Med. 108:473-478.

24. Park, C.H., Bacon, B.R., Brittenham, G.M., and Tavill, A.S. 1987. Pathology of dietary carbonyl iron overload in rats. Lab. Invest. 57:555-563.

25. LeBoeuf, R.C., Tolson, D., and Heinecke, J.W. 1995. Dissociation between tissue iron concentrations and transferrin saturation among inbred mice. J. Lab. Clin. Med. 126:128-136.

26. Plump, A.S., et al. 1992. Severe hypercholesterolemia and atherosclerosis in apolipoprotein E-deficient mice created by homologous recombination in ES cells. Cell. 71:343-353.

27. Zhang, S.H., Reddick, R.L., Piedrahita, J.A., and Maeda, N. 1992. Spontaneous hypercholesterolemia and arterial lesions in mice lacking apolipoprotein E. Science. 258:468-471.

28. Leeuwenburge, C., et al. 1997. Mass spectrometric quantification of markers for protein oxidation by tyrosyl radical, copper, and hydroxy radical in low density lipoprotein isolated from human atherosclerotic plaques. J. Biol. Chem. 272:3520-3526.

29. Gutteridge, J.M.C., Rowley, D.A., and Halliwell, B. 1981. Superoxidedependent formation of hydroxyl radicals in the presence of iron salts. Biochem. J. 199:263-265.

30. Sohal, R.S., Wenneberg-Kirch, E., Jaiswal, K., Kwong, L.K., and Forster, M.J. 1999. Effect of age and caloric restriction on bleomycin-chelatable and nonheme iron in different tissues of C57BL/6 mice. Free Radic. Biol. Med. 27:287-293.

31. Rozen, S., and Skaletsky, H.J. 1996, 1997. http://www.genome. wi.mit.edu/cgi-bin/primer/primer3.cgi/.

32. National Center for Biotechnology Information http://www2.ncbi. nlm.nih.gov/genbank/

33. Kunjathoor, V.V., Wilson, D.L., and LeBoeuf, R.C. 1996. Increased atherosclerosis in streptozotocin-induced diabetic mice. J. Clin. Invest. 97:1767-1773.

34. Huggins, T.G., Wells-Knetch, M.C., Detorie, N.A., Baynes, J.W., and Thorpe, S.R. 1993. Formation of o-tyrosine and dityrosine in proteins during radiolytic and metal-catalyzed oxidation. J. Biol. Chem. 268:12341-12347.

35. Karlefors, T., and Nordem, A. 1958. Studies on iron-dextran complex. Acta Med. Scand. 163:5342, 1-54.

36. Bothwell, T.H., Charlton, R.W., Cook, J.D., and Finch, C.F. 1979. Iron metabolism in man. Blackwell Science. Malden, Massachusetts, USA. pp79.

37. Bothwell, T.H., Charlton, R.W., Cook, J.D., and Finch, C.F. 1979. Iron metabolism in man. Blackwell Science. Malden, Massachusetts, USA 105-172.

38. Smith, L.H., Jr. 1990. Overview of hemochromatosis. West. J. Med. 153:296-308

39. Miller, M., and Hutchins, G.M. 1994. Hemochromatosis, multiorgan hemosiderosis, and coronary artery disease. JAMA. 272:231-233.

40. Battiloro, E., et al. 2000. Haemochromatosis gene mutations and risk of coronary artery disease. Eur. J. Hum. Genet. 8:389-392.

41. Calado, R.T., et al. 2000. HFE gene mutations in coronary atherothrombotic disease. Braz. J. Med. Biol. Res. 33:301-306.

42. Annichino-Bizzacchi, J.M., et al. 2000. C282Y mutation in the HLA-H gene is not a risk factor for patients with myocardial infarction. J. Cardiovasc. Risk. 7:37-40.

43. Roest, M., et al. 1999. Heterozygosity for a hereditary hemochromatosis gene is associated with cardiovascular death in women. Circulation. 100:1268-1273

44. Tuomainen, T.P., et al. 1999. Increased risk of acute myocardial infarction in carriers of the hemochromatosis gene Cys282Tyr mutation: a prospective cohort study in men in eastern Finland. Circulation. 100:1274-1279.

45. Gutteridge, J.M., Mumby, S., Koizumi, M., and Taniguchi, N. 1996 "Free" iron in neonatal plasma activates aconitase: evidence for biologically reactive iron. Biochem. Biophys. Res. Commun. 229:806-809.

46. Knutson, M.D., Walter, P.B., Ames, B.N., and Viteri, F.E. 2000. Both iron deficiency and daily iron supplements increase lipid peroxidation in rats. J. Nutr. 130:621-628.

47. Ishikawa, K., Navab, M., Leitinger, N., Fogelman, A.M., and Lusis, A.J 1997. Induction of heme oxygenase- 1 inhibits the monocyte transmigration induced by mildly oxidized LDL. J. Clin. Invest. 100:1209-1216.

48. Stocker, R. 1990. Induction of haem oxygenase as a defense against oxidative stress. Free Radic. Res. Comun. 9:101-112.

49. Liao, F., Andalibi, A., deBeer, F.C., Folgelman, A.M., and Lusis, A.J. 1993. Genetic control of inflammatory gene induction and NF-kappa B-like transcription factor activation in response to an atherogenic diet in mice. J. Clin. Invest. 91:2572-2579.

50. Berliner, J.A., et al. 1995. Atherosclerosis: basic mechanisms. Oxidation, inflammation, and genetics. Circulation. 91:2488-2496.

51. Klausner, R.D., Rouault, T.A., and Harford, J.B. 1993. Regulating the fate of mRNA: the control of cellular iron metabolism. Cell. 72:19-28.

52. Dlaska, M., and Weiss, G. 1999. Central role of transcription factor NFIL6 for cytokine and iron-mediated regulation of murine inducible nitric oxide synthase expression. J. Immunol. 162:6171-6177.

53. Juckett, M.B., et al. 1995. Ferritin protects endothelial cells from oxidized low density lipoprotein in vitro. Am. J. Pathol. 147:782-789.

54. Vercellotti, G.M., et al. 1994. Heme and the vasculature: an oxidative hazard that induces antioxidant defenses in the endothelium. Artif. Cells Blood Substit. Immobil. Biotechnol. 22:207-213. 